\title{
VULNERABILITY ASSESSMENT OF DWELLINGS IN THE HISTORIC CENTER OF CUSCO (PERU)
}

\author{
G. BRANDO $^{1 *}$, G. COCCO ${ }^{1}$, C. MAZZANTI ${ }^{1}$, M. PERUCH ${ }^{1}$, E. SPACONE $^{1}$, C. \\ ALFARO $^{2}$, K. SOVERO ${ }^{2}$ AND N. TARQUE ${ }^{3}$ \\ ${ }^{1}$ Department of Engineering and Geology, \\ University "G. d'Annunzio' of Chieti Pescara, Pescara, Italy \\ email: gbrando@unich.it (*corresponding author) \\ ${ }^{2}$ Department of Engineering, Urb. Ingegneria Larapa Grande A-5 \\ Universidad Andina del Cusco \\ San jeronimo, Cusco 08006, Peru \\ ${ }^{3}$ Department of Engineering \\ Pontifical Catholic University of Peru (PUCP) \\ San Miguel 15088, Peru
}

Keywords: Seismic Vulnerability, Historic center, Cusco, Adobe, UNESCO sites

\begin{abstract}
The seismic vulnerability assessment of the historic center of Cusco (Peru), an important UNESCO world heritage site, is dealt with in this paper. First, historical development of the city is presented through an in-depth historical analysis of its transformation over time, from the Inca empire to modern days. Then, an extensive in-situ survey activity, that allowed to collect several information about the main structural features concerning ordinary residential buildings, is shown.

Based on the collected data, an empirical method calibrated on Italian historic centers from the authors is applied. It allowed to obtain Damage Probability Matrices and Fragility Curves for different earthquake intensities, as well as to assess the probability of exceeding certain levels of damage when seismic events of different intensities occur.

Based on these predicted damage frequencies, it is possible to prevent irremediable losses and to propose retrofitting interventions which can lead to the seismic vulnerability mitigation for the whole historic center.
\end{abstract}

\section{INTRODUCTION}

Seismic vulnerability of buildings is defined as their aptitude to present damages or collapses due to seismic events. Considering the frequent occurrence of earthquakes, seismic vulnerability assessment is an essential process for building heritage preservation, especially when it is applied to UNESCO word heritage sites such as Cusco, which is dealt with in this paper.

The Seismic Vulnerability Assessment is an issue that can be managed in different ways, to be selected based on the problem size and the resources available. When the stock of buildings to analyze is quite large, empirical methods represent an expeditious way for an assessment at 
the urban scale, based on engineering judgments and statistical data elaboration [1],[2]. Conversely, numerical methods, based on FEM (Finite Element Method) models characterized by a high computational effort and time-consuming, allow to focus the attention on the seismic response of a single building [3],[4], [5]. This kind of methodology is mainly used in case of structures with an important historical/cultural/architectonical value. However, analyses with a medium complexity can be applied by means analytical methods that, focusing the attention on a stock of buildings considered representative of the whole historic center, allow to perform analyses that are more feasible with respect to numerical analyses but more detailed in comparison to the empirical methods [6],[7], [8] .

The methodology applied to the historic center of Cusco, presented in this paper, is an empirical vulnerability index-based method, in which Vulnerability Indices were obtained through observation procedures that have involved many residential adobe structures. The application of this procedure allowed to evaluate the main vulnerability sources and, therefore, to propose possible interventions aimed at mitigating the seismic risk of the whole historic center.

To estimate the Vulnerability Indices, it was necessary to carry out a preliminary study concerning the historical evolution of the historic center and an in-situ investigation in order to collect all useful information, presented in Section 2 and 3. The applied Vulnerability Indexbased Method is explained in Section 4. Finally, Damage Probability Matrices, provided by the method, and the related Empirical Fragility Curves are shown in Section 5.
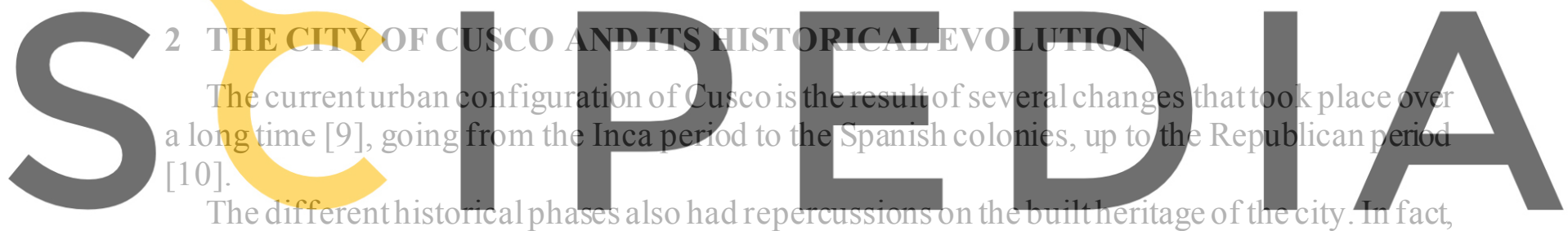
the urban configuration of Cusco passed from the presence of common squares surrounded by

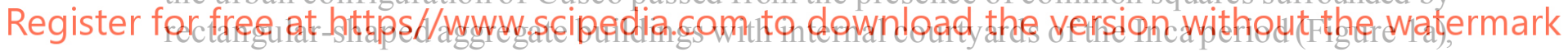

to the reduction of the common squares extensions, during the Spanish domination, with the construction of adobe buildings atop the ancient walls of the Inca period that worked as foundations (Figure 1b), [11].

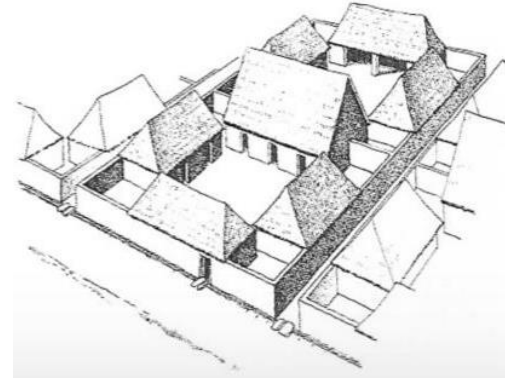

a)

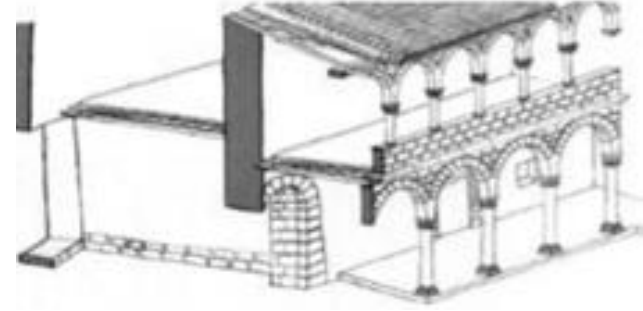

b)

Figure 1: Evolution of structural typologies in Cusco: from the "kancha" of the Inca period (a) to the colonial houses of the Spanish domination (b). 
Despite the succession of building types characterizing each historical phase, one of the main factors that influenced the built heritage evolution of Cusco was the relevant seismic activity in the area. Several seismic events led to continuous processes of reconstruction, shaping and reshaping the configuration of the city, such as the one implemented after the destructive 1950 earthquake, which led to the collapse of several structures including adobe buildings, colonial churches, but also new structures [12].

In addition, the large flow of tourists that every year involve the historic center of Cusco has been the cause of the growing demand for hotels and shops located in the heart of the historic center. For this reason, most of the adobe houses located close to the hugest squares experienced changes of use and deep structural modifications, which led to the loss of the original vernacular structure's identity.

\section{THE STRUCTURAL SURVEY OF ADOBE DWELLINGS}

In order to assess the seismic vulnerability of dwellings in the historic center of Cusco, a reconnaissance activity characterized by rapid surveys was necessary. A special form to collect all necessary data was used for the purpose [13]. Each survey form served to identify the main features of each structural unit belonging to a building aggregate: type of material, number of floors, structural system typology, foundation system, ro of characteristics, façade thickness and site topographical features.

However, it has not been possible always to inspect all buildings from inside and, in some

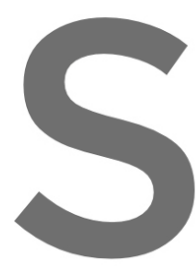
cases, the survey was activity allowed to ascert while the remaining 2
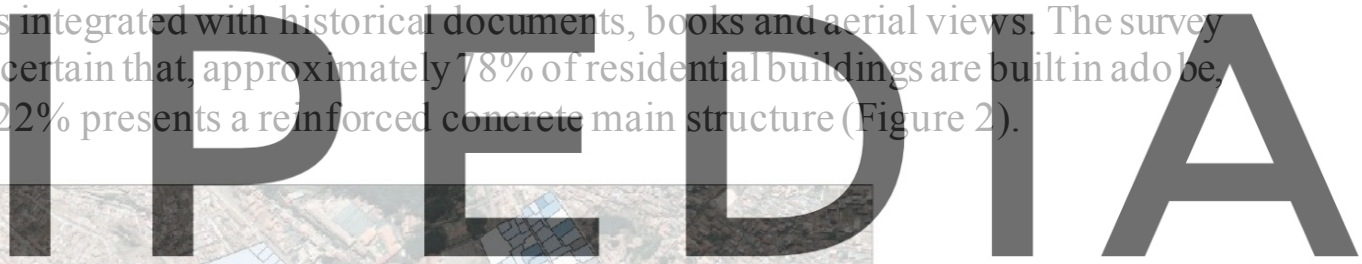

Register for free at https//www.scipedia.com to download the version without the watermark

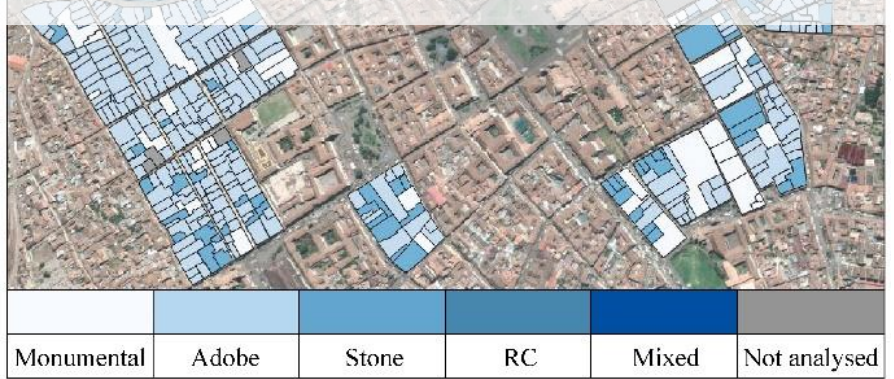

Figure 2: Map of Cusco and territorial distribution of the main structural typologies.

Focusing the attention on adobe structural units, they are mostly organized on two or three floors, with a height of about $2.5 \mathrm{~m}$. The adobe walls thickness ranges from $80 \mathrm{~cm}$ to $100 \mathrm{~cm}$. The foundation system extends above the street level, to isolate the adobe walls from the humidity rising from the ground: stone foundations have been identified in about $77 \%$ of the 
analyzed buildings (Figure 3a), however, in $2 \%$ of the structures the ancient Inca foundations are still recognizable (Figure $3 \mathrm{~b}$ ). These are made of very large granite blocks dry assembled. Floors and roofs are made of wooden structures which, due to the poor connections with the vertical walls, do not guarantee any type of restrain. Furthermore, sporadically, steel ties or ring beams that act as anti-seismic devices have been identified.

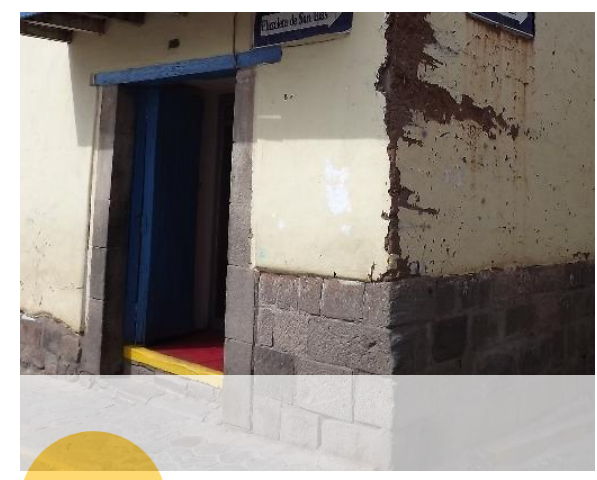

a)

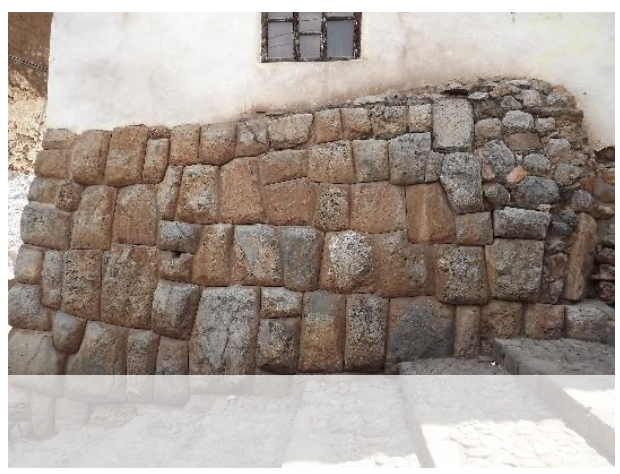

b)

Figure 3: Main foundation typologies: the most recent stone foundations (a) and the ancientInca foundations (b).

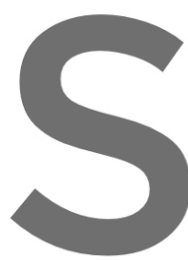

Single structural unit called "cuadra", which which are surrounded b possible evacuation routes in survey form. This repre collapse of a façade overlooking that street.
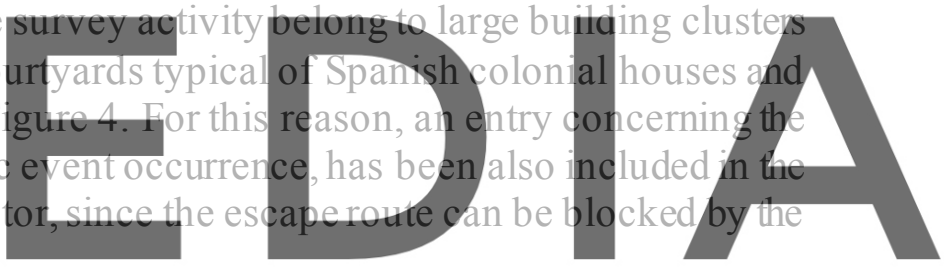

The collection of all these data and their statistical re-elaboration, allowed to ascertain that

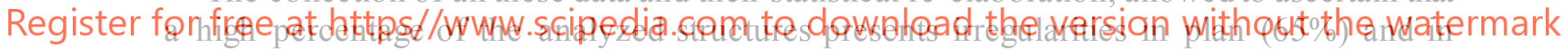
elevation (96\%), poor quality connections and total absence of seismic protection (80\%) [14].

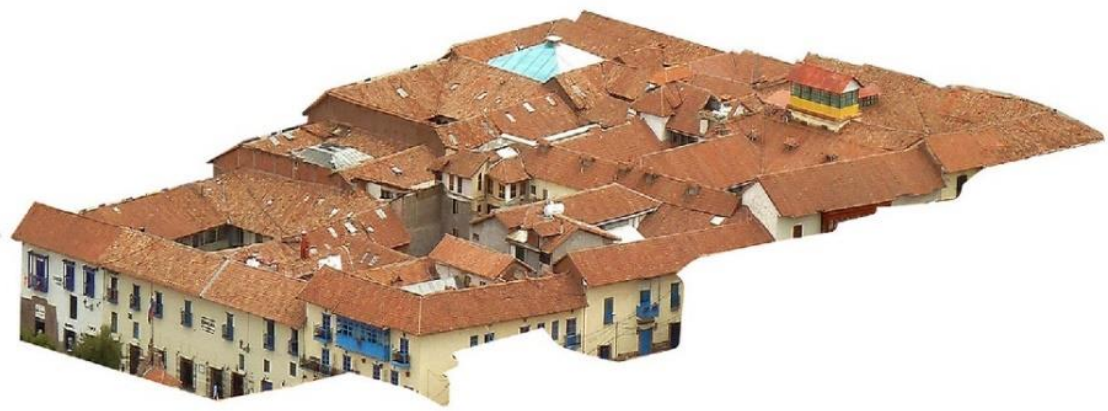

Figure 4: Gra phic representation of a typical block in the historic center of Cusco. 


\section{THE VULNERABILITY INDEX-BASED METHOD}

An empirical methodology has been applied. In detail, the data collected during the in-situ investigations through observational procedures were used to evaluate vulnerability indices for adobe dwellings.

A Vulnerability-index for each adobe dwelling presents in the historic center of Cusco has been defined, considering the seven vulnerability parameters reported in Table 1 . These parameters come from a Vulnerability-Index Based Method calibrated through the damage observation of masonry buildings belonging to the Italian historic centers [15], which led to the definition of fourteen Vulnerability Parameters. However, considering the different structural typologies present in Cusco and their main vulnerability sources, only seven of them have been considered.

Table 1: Vulnerability parameters Pi considered for the proposed VI Method

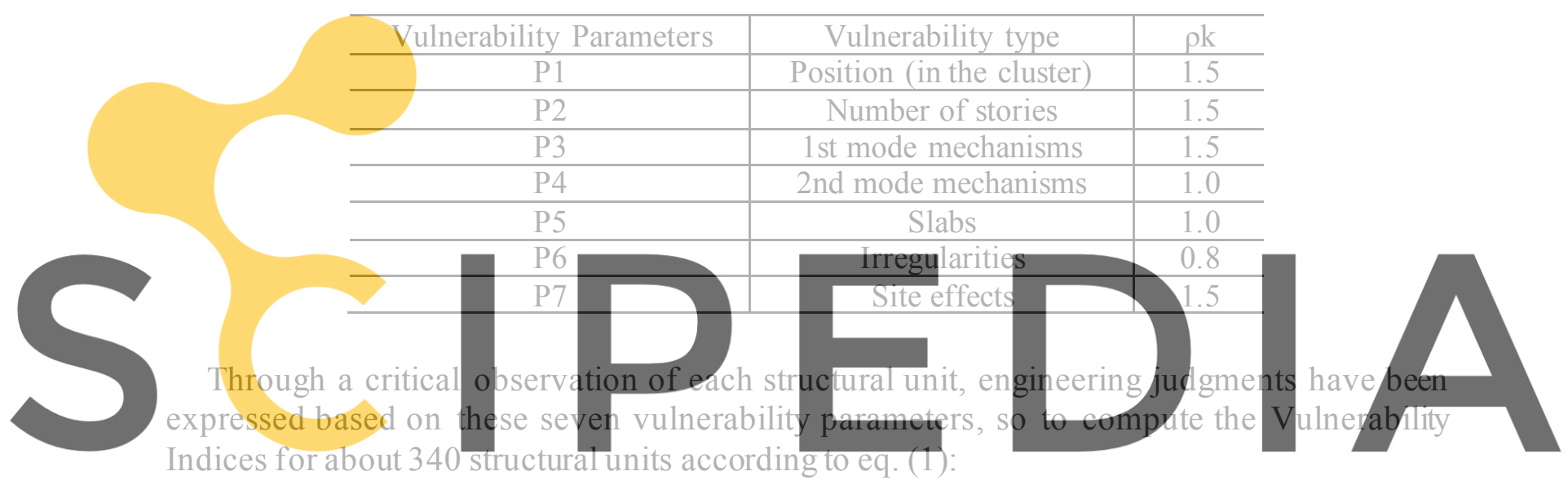

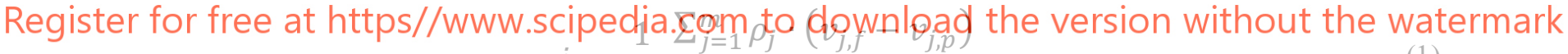
$i_{v}=\frac{1}{6} \cdot \frac{j}{\sum_{j=1}^{m} \rho_{j}}$

Where:

- $\quad \rho$ is a factor that weight the influence of the general parameter on the whole stability of the building. It was calibrated based on damage reconnaissance activities carried out on masonry buildings and its value can range from 0 to 1.5 [15];

- $\quad v_{j, f}$ is the fragility score that is higher as the structural feature makes the vulnerability sources more severe;

- $\quad v_{j, p}$ is defined as the protection score which consider the effectiveness of the applied anti-seismic device in order to contrast the development of undesired mechanisms related to the vulnerability source $P_{k}$.

Once the vulnerability indices for the considered structural units have been defined, their average value $i_{v}^{*}$ has been computed. This allows the definition of the so-called vulnerability factor $V$, suitably calibrated in [15] and defined by eq. (2): 


$$
V=0.53+1.16 \cdot i_{v}^{*}-4.00 \cdot i_{v}^{* 2}+4.21 \cdot i_{v}^{* 3}
$$

This factor allowed the definition of an expected mean damage value $\mu_{D}$ by means of eq. (3). It has been computed for different seismic intensities $I_{M C S}$ (expressed in the Mercalli - Cancani - Sieberg Scale-MCS) and considering the ductility of analyzed buildings through the factor $Q$, set equal to 2.3 .

$$
\mu_{D}=2.5 \cdot\left[1+\tanh \left(\frac{I_{M C S}+6.25 \cdot V-13.1}{Q}\right)\right]
$$

Then, the mean damage $\mu_{D}$ has been used to evaluate the probability $p[k \mid I]$ of achievement of a certain damage level $k$ for each seismic intensity $I_{M C S}$, through a binomial probability distribution expressed by eq. (4):

$$
p\left[k \mid I_{M C S}\right]=\frac{5 !}{k ! \cdot(5-k) !} \cdot\left(\frac{\mu_{D}}{5}\right)^{k} \cdot\left(1-\frac{\mu_{D}}{5}\right)^{5-k}
$$

The coefficient $k$ represents the damage level according to Grünthal [16]. It can vary from 0 to 5 based on the damage extension:

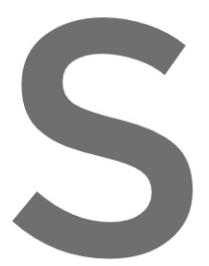

$\mathrm{k}=0$ No structural damage;

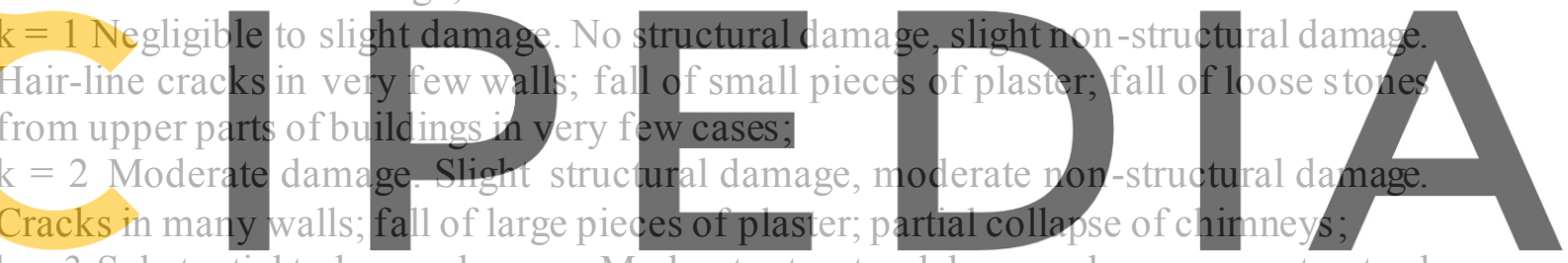

$\mathrm{k}=3$ Substantial to heavy damage. Moderate structural damage, heavy non-structural Register for free at het Large and extensive cracks in most walls irof tiles detach: chimneys fracture

$\mathrm{k}=4$ Very heavy damage. Heavy structural damage, very heavy non-structural damage.

Serious failure of walls; partial structural failure of roofs and floors.

- $\quad k=5$ Destruction. Very heavy structural damage. Total or near total collapse.

\section{FINAL RESULTS}

The empirical methodology implemented in this study allowed to assess the expected damage scenarios through the Damage Probability Matrices (DPMs) for different seismic intensities $I_{M C S}$. These are shown in Figure 5a and allow to assess how the damage scenarios evolve when the seismic intensity increases. Moreover, by summing the estimations coming from the DPMs, it was possible to define the Fragility Curves, shown in Figure 5b. They represent the probability of exceeding a certain damage level $P[D>D k]$, in relation to a given Peak Ground Acceleration $(P G A)$. To move from the Macroseismic Intensity $I_{M C S}$, in which the Damage Probability Matrices are expressed, to the $P G A$, the relation proposed by Margottini in 1992 was used [17].

Information that can be derived from these Fragility Curves are of considerable importance. For instance, if Cusco is hit by an earthquake characterized by a PGA/g equal to 0.6 , the fragility 
curves allow to predict the following damage scenario: about $60 \%$ of the buildings will have total collapses or collapses affecting more than $50 \%$ of the structure (D > D4); serious damage (D > D3) recognizable by large cracks and activation of overturning mechanisms, will affect $30 \%$ of the analyzed buildings; while, the remaining $10 \%$ of the examined stock will suffer damages that go from negligible to moderate (D0 $<$ D $<$ D3).

The vulnerability index-based method not only allows a prediction of the expected damage scenarios, but also a critical assessment of the structural deficiencies found, as well as possible proposal of interventions, through the analysis of fragilities $\left(v_{j, f}\right)$ and protections $\left(v_{j, p}\right)$ (Figure $6 \mathrm{a}$ and $6 \mathrm{~b}$ ), computed according to the procedures previously presented.

From their analysis it was possible to notice that, most of the buildings belonging to the analyzed stock, have a high vulnerability with respect to overturning mechanisms and site effects. Although the latter cannot be avoided in any way, the undesired kinematic mechanisms can be limited through the insertion of anti-seismic devices, like iron ties or buttresses, able to restrain more effectively vertical walls. These interventions, if implemented on an urban scale, would lead to a lowering of the average vulnerability index $i_{v}^{*}$ from 0.72 to 0.65 [12]. If further interventions are added, so to also improve the slab performance and to enhance the wall textures, a remarkable seismic vulnerability mitigation of the whole historic center of Cusco would be achieved.
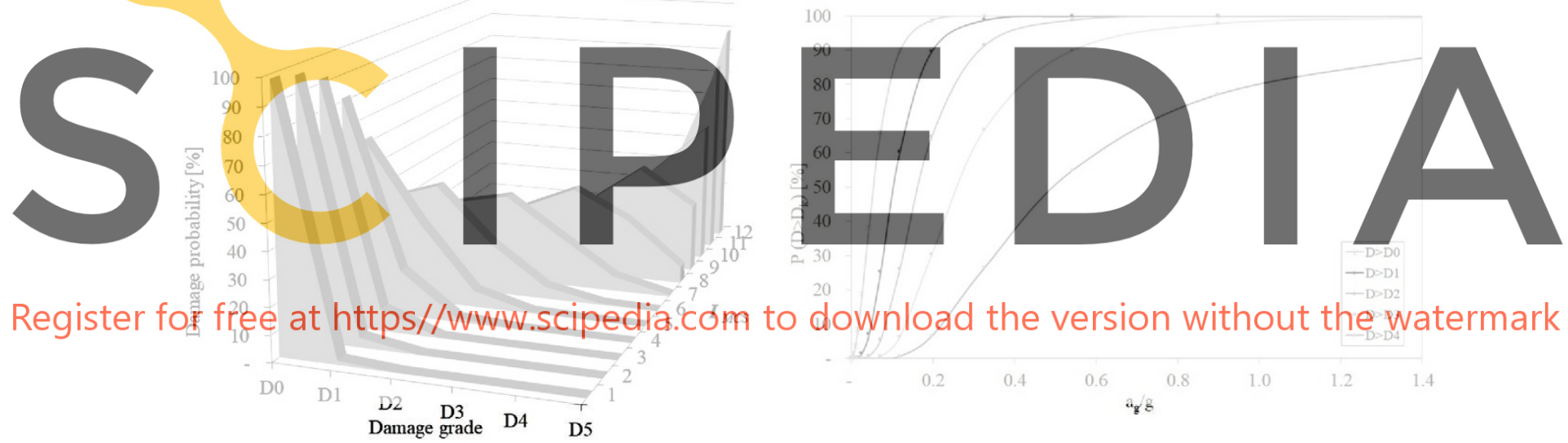

Register for free at https//www.scipedia.com to download the version without the watermark Damage grade D4 D5

Figure 5: Expected Damage Scenarios represented by means of Damage Probability Matrices (a) and Fra gility Curves in terms of Peak Ground Acceleration (b). 


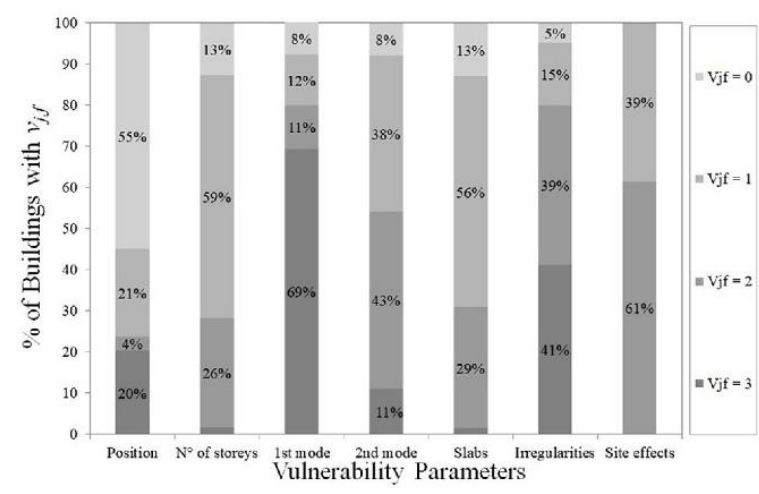

a)

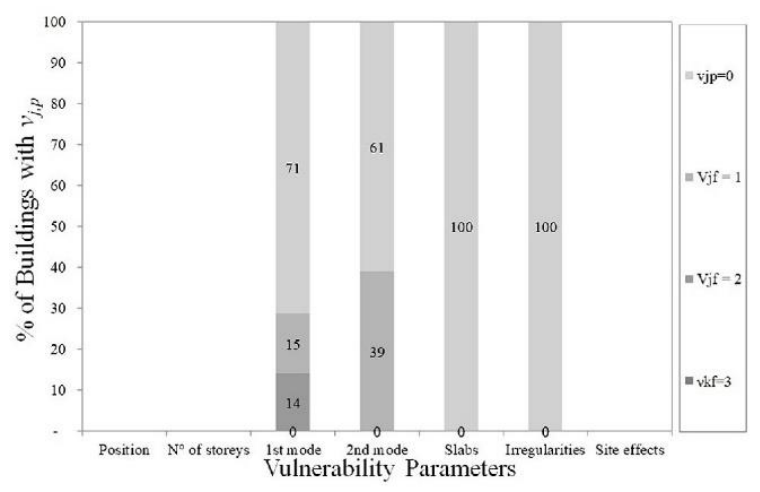

b)

Figure 6: Statistical distribution of thescores (a) $v_{\mathrm{mf}}$ and (b) $v_{\mathrm{mp}}$.

\section{CONCLUSIONS}

This paper dealt with the seismic vulnerability assessment, carried out on the urban scale of a large area of the historic center of Cusco, in Peru, focusing the attention on adobe dwellings. This analysis was carried out through the application of an empirical methodology calibrated on masonry buildings belonging to several Italian historic centers and adapted to the building

The first phase of analysis was historical-c evolution processes of the historic center. After th of all needful data for the seismic vulnerability
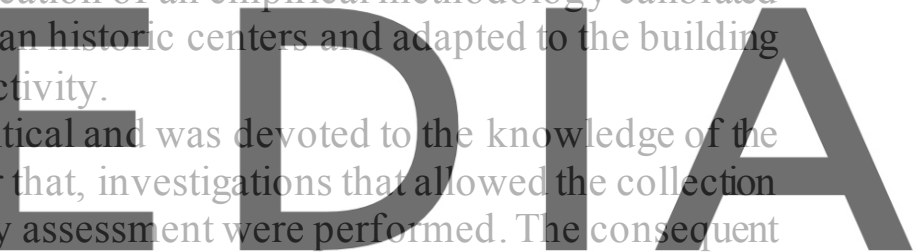

Vulnerability Indices computation allowed to elaborate the expected damage scenarios for

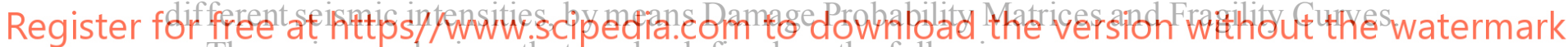
The main conclusions that can be defined are the following:

the current configuration of the historic center of Cusco and its buildings are the result of several transformation processes, mostly related to the seismic history of the area;

- the analyzed buildings are characterized by a structural organization on two or three floors with stone foundations, wooden horizontal slabs and poor connections;

- the most common vulnerability sources are related to the lack or ineffectiveness of seismic prevention devices able to guarantee an effective connection of the orthogonal walls and between vertical and horizontal elements;

- since the implemented method represents a procedure calibrated on Italian masonry buildings, with characteristics that are different from the Peruvian adobe dwellings, the results will have to be confirmed by means of more detailed analysis.

Acknowledgements. The study presented in this paper was carried out within the framework of an ongoing cooperation agreement signed in 2017 between the University of Chieti-Pescara (Italy), the Andina University del Cusco (Peru) and the Pontifical Catholic University of Peru (Peru). 


\section{REFERENCES}

[1] Rapone, D., Brando,G. Spacone, E. and De Matteis, G. "Seismic vulnerability assessment of historic centers: description of a predictive method and application to the case study of Scanno (Abruzzi, Italy),” Int. J. Archit. Herit., vol. 12, no. 7-8, pp. 1171-1195, 2018.

[2] Ferreira, T. M., Vicente, R., Silva, J. A. R. M., Varum, H. and Costa, A. "Seismic vulnerability assessment of historical urban centres: case study of the old city centre in Seixal, Portugal,” Bull. Earthq. Eng., vol. 11, no. 5, pp. 1753-1773, 2013.

[3] Tarque, N., Crowley, H., Pinho, R. and Varum, H. "Seismic capacity of adobe dwellings," Proc. 14th Eur. Conf. Earthq. Eng., no. September 2014, 2010.

[4] Illampas, R., Charmpis, D. C. and Ioannou, I. "Non-linear Dynamic Finite Element Analy sis of Adobe Masonry Structures with Various Roof Diaphragm Configurations," pp. 475-487, 2015.

[5] Brando, G., Criber, E., De Matteis, G. The effects of L'aquila earthquake on the St. Gemma church in Goriano Sico li: part II - fem analysis (2015) Bulletin of Earthquake Engineering 13 (12), pp. 3733-3748.

[6] Allahvirdizadeh, R., Oliveira, D. V. and Silva, R. A. "Modelling the seismic out - of - plane behaviour of rammed earth components modelling," no. September, pp. 19-21, 2018.

[7] Cocco, G., D'Aloisio, A., Spacone, E. and Brando, G. "Seismic Vulnerability of Buildings in Historic Centers: From the 'Urban' to the 'Aggregate' Scale," Front. Built Environ., vol. 5, no. June, pp. 1-14, 2019.
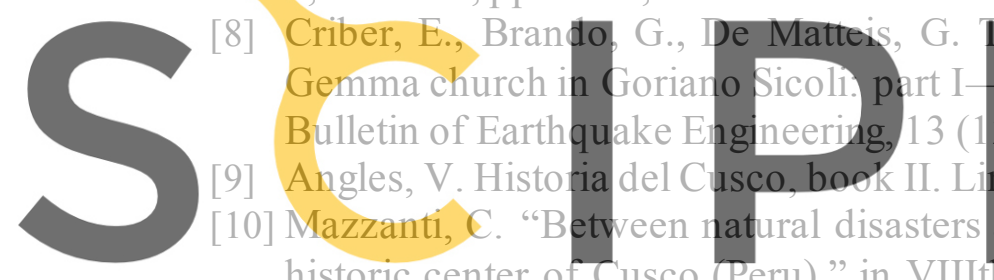
historic center of Cusco (Peru)," in VIIIth CIRTCE ]

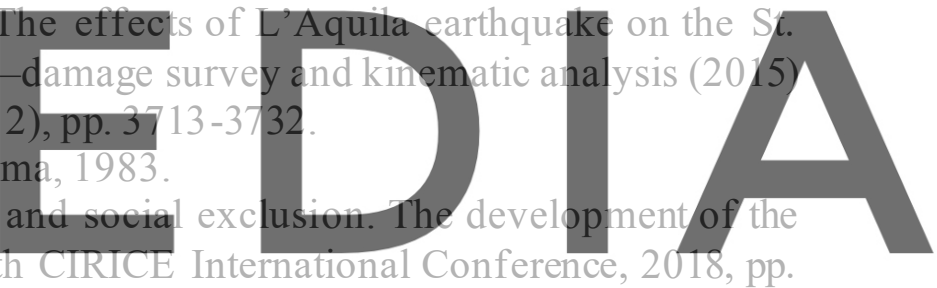
483-490

Register for free at httpst wsw:scipedia.for to d edwoligad the versign without the watermark sim bòlicas. Lima, 2004

[12] Samanez, R. "El terremoto que afectò a Cusco en 1950 y los aportes de George A. Kubler,' Arkinka, vol. 16, no. 204, pp. 91-95, 2012.

[13] Spacone, E., Brando, G., Peruch, M., Mazzanti, C., Sovero, K. and Tarque, N. "An extensive survey of the Historic Center of Cusco for its seismic vulnerability assessment," RILEM Bookseries, vol. 18, 2019.

[14] Brando, G., Cocco, G., Mazzanti, C., Peruch, M., Spacone, E., Alfaro, C., Sovero, K. and Tarque, N. "Structural Survey and Empirical Seismic Vulnerability Assessment of Dwellings in the Historical Centre of Cusco, Peru," Int. J. Archit. Herit., pp. 1-29, 2019.

[15] Brando, G., De Matteis, G. and Spacone, E. "Predictive model for the seismic vulnerability assessment of small historic centres: Application to the inner Abruzzi Region in Italy," Eng. Struct., vol. 153, no. December 2016, pp. 81-96, 2017.

[16] Grünthal, G. European Macroseismic Scale, vol. 15. Luxembourg, 1998.

[17] Margottini, C., Molin, D., Narcisi, B. and Serva, L. "Intensity vs acceleration: Italian data," Proc. Work. Hist. Seism. Cent. Mediterr. Reg., pp. 213-226, 1987. 